\title{
Management of non-specific urethritis in men
}

\section{Evaluation of six treatment regimens and effect of other factors including alcohol and sexual intercourse*}

\author{
O. P. ARYA, $\dagger$ C. D. AlERGANT, $\dagger$ E. H. ANNELS, $\dagger$ P. B. CAREY, $\dagger$ \\ A. K. GHOSH, $†$ AND A. D. GODDARD \\ From the †Department of Venereology, University of Liverpool, and Liverpool Area Health \\ Authority (Teaching), Liverpool Royal Infirmary; and $\ddagger$ Computer Laboratory, University of Liverpool, \\ Liverpool
}

SUMMARY A trial comparing the efficacy of three different tetracyclines, each in two different dosage regimens, in the treatment of non-specific urethritis is described. There was a significant association between the retreatment rate and sexual intercourse. Age, race, duration of symptoms, previous infection, and indulgence in alcohol did not appear to influence the results whereas treatment of sexual contacts before resumption of sexual intercourse significantly reduced the retreatment rate. Single-dose treatment with doxycycline was shown to be ineffective. Treatment with doxycycline for seven days or triple tetracycline for seven days was less effective than triple tetracycline for 21 days or oxytetracyline for seven or 21 days, all of which gave the same success rate.

\section{Introduction}

Non-specific urethritis (NSU) is the commonest sexually transmitted disease in the United Kingdom (Department of Health and Social Security, 1976) and is very common in the USA (Wiesner, 1977). There is evidence that this condition is also common in some of the developing areas of the world (Arya, 1972; Osoba, 1972).

The optimum management of NSU continues to pose problems for the following reasons:

1. The aetiology (notwithstanding the role of Chlamydia trachomatis) remains a mystery;

2. The natural history is not clear;

3. Diagnostic criteria and evaluation of treatment are ill defined.

Earlier workers (King, 1964; British Medical Journal, 1971) drew attention to problems such as the variation in severity and duration of the disease, which are often not stated and which may affect the outcome of treatment. Other factors deserving attention when treatment is evaluated are age, race, past history, sexual behaviour, and alcohol consumption.

* Paper presented at the Spring Meeting of the Medical Society for the Study of Venereal Diseases, Leeds, 19-21 May 1978

Address for reprints: O. P. Arya, Department of Venereology, Liverpool Royal Infirmary, Liverpool, L3 5PU

Received for publication 22 February 1978
While tetracyclines are considered to be the mos effective remedy (Willcox, 1972) there is no agree ment on the preparation, the dose, and the duration of treatment. Over a score of treatment regimens of various tetracyclines have been tried. These range from a single dose of doxycycline (Masterton and Schofield, 1972) to a 21-day course of oxytetracycline (John, 1971). All regimens have their advocates. The results of several studies are not strictly comparable because of the differences in the diagnostic criteria used. Very few studies have matched the outcome of treatment with variables of severity and duration of symptoms, past history, consumption of alcohol, et cetera.

More recently $C$. trachomatis has been suggested as an important cause of nongonococcal urethritis (Holmes et al, 1975; Oriel et al, 1976). If that is accepted, then a search should be made for the treatment regimens appropriate to Chlamydiapositive and Chlamydia-negative patients with urethritis. It is unlikely, however, that public health laboratories in this country or elsewhere will provide a service for routine Chlamydia isolation in the foreseeable future. Treatment of NSU, therefore, in most parts of the world will continue to be empirical. An ideal regimen for any area must be the one which has been proved to be highly effective locally, because of the possibility of strain differences as well as different aetiological agents as yet un- 
known, and takes into account the problems of cost and drug compliance.

Some of the points raised above prompted us to evaluate six drug regimens, including one of a single dose. The concept of a single-session regimen in the treatment of NSU is not new. Alergant (1964) found a combination of $0.5 \mathrm{~g}$ streptomycin intramuscularly and two tablets of $0.5 \mathrm{~g}$ sulphamethoxydiazine (Durenate) as good as the conventional five-day treatment used in those days. Mahony et al (1972), using a single-session regimen comprising oral sulfametopyrazine $(2 \mathrm{~g})$ and intramuscular streptomycin (1g), obtained a cure rate of $82 \%$ after 10-14 days' follow up. Doxycycline, which is claimed to give higher and more prolonged serum and tissue concentrations than standard tetracyclines, had earlier been proved to be highly effective $(93.3 \%$ cure rate) in a single dose of $300 \mathrm{mg}$ in the treatment of NSU (Masterton and Schofield, 1972). This last regimen could obviously be a major breakthrough in the management of NSU. We, therefore, thought it necessary to reassess it.

The subsidiary aims of this study were to investigate the effects of the following factors on the outcome of treatment:

1. Age, race, past history, severity of symptoms and their duration, and signs (with a view to predicting the optimum treatment for a given patient);

2. Alcohol;

3. Sexual intercourse.

\section{Material and methods}

\section{ST UDY POPULATION}

New cases of uncomplicated NSU seen at the Seamen's Dispensary from 18 October 1974 to 17 October 1976 were included in the trial. Patients were excluded if they had had a history of gonorrhoea or NSU during the preceding three months; if the present episode had been treated with sulphonamides or antibiotics; if there was no likelihood of the patient completing at least one month's follow up; or if there was a history of tetracyciine hypersensitivity. NSU was diagnosed after gonorrhoea had been excluded by negative results to urethral smear and culture and if urethral discharge or urine threads showed more than 15 polymorphonuclear leucocytes in more than five high power fields ( $\times 500$ objective $\times$ 5 binocular eyepiece). The same microscopist examined the smears throughout the study.

DRUG REGIMENS AND PATIENT GROUPS The 756 patients and the six regimens were grouped as follows: group 1, doxycycline $300 \mathrm{mg}$ in a single dose (58 patients); group 2, oxytetracycline $250 \mathrm{mg}$ six-hourly for seven days (156 patients), or triple tetracycline (containing chlortetracycline hydrochloride $115.4 \mathrm{mg}$, tetracycline hydrochloride $115.4 \mathrm{mg}$, and demeclocycline hydrochloride 69.2 $\mathrm{mg}$ ) 12-hourly for seven days (152 patients), or doxycycline $200 \mathrm{mg}$ on the first day followed by $100 \mathrm{mg}$ daily for six days (132 patients); and group 3 , oxytetracycline $250 \mathrm{mg}$ six-hourly for 21 days (138 patients), or triple tetracycline $300 \mathrm{mg} \mathrm{12-}$ hourly for 21 days (120 patients). The regimens were allocated by weekly rotation. Doxycycline in a single dose was administered under supervision. One week's supply only of a drug was dispensed at a time to those allocated the 21-day regimens.

Patients were to be followed up after one, two, three, five, eight, and 12 weeks after starting treatment. They were advised not to pass urine for at least three hours before each attendance, not to indulge in self-examination, and to abstain from alcohol for three weeks and from sexual intercourse for five weeks. At each follow-up visit inquiries were made concerning further sexual intercourse, consumption of alcohol, urethral discharge and urinary or other symptoms, interim medication, and hours since urine was last passed. At each follow-up visit urethral discharge or urinary threads if present were sampled for microscopical examination. Treatment was considered to have failed if a urethral discharge reappeared or persisted after the completion of treatment; if urinary threads (in the absence of urethral discharge) showed more than 15 polymorphonuclear leucocytes in more than five high power fields ( $\times 500$ magnification) two weeks or more after the completion of treatment; or if there were complications.

Patients were encouraged to ask their sexual contacts to attend the female clinics at the Liverpool Royal Infirmary, where the usual tests-including those for Chlamydia-were carried out. Contact slips were issued, and in many cases appointments were arranged at the same time.

All information was recorded on precoded proformas designed for computer analysis with the SPSS (Statistical Package for Social Sciences) programme. Tests for significance were performed by means of the $\chi^{2}$ test with Yates's correction.

\section{Results}

DEMOGRAPHIC DATA AND CLINICAL DETAILS

A total of 756 patients were included in the trial. The demographic data and clinical details were similiar for all treatment groups. 
Age

Over half $(52 \cdot 2 \%)$ of patients were aged $20-29$ and only $3 \%$ were 50 or over.

\section{Race}

Eighty-two per cent of patients were white and $18 \%$ were black or coloured.

\section{Marital state}

Over half $(58.7 \%)$ of patients were single, $33.9 \%$ married, and $7 \cdot 4 \%$ divorced, widowed, or separated.

\section{Past history}

Of the 756 patients $48 \cdot 1 \%$ had never had any sexually transmitted disease, $24 \cdot 1 \%$ had had gonorrhoea, $19 \cdot 6 \% \mathrm{NSU}$, and $4 \cdot 1 \%$ gonorrhoea as well as NSU.

\section{Source of infection}

Source of infection was known in $64 \%$ and unknown in $36 \%$.

\section{Symptoms}

Forty-eight per cent complained of urethral discharge, $13.8 \%$ had urinary symptoms, $23 \%$ had experienced urethral discharge as well as urinary symptoms, $8.7 \%$ complained of irritation in the penis, and the remaining $6.5 \%$ were asymptomatic.

\section{Presence of urethral discharge}

Urethral discharge was present at the first attendance in $54 \%$ (mucoid in $25 \%$ and purulent or mucopurulent in $29 \%$ ). Over half of the remaining $46 \%$ who had no demonstrable urethral discharge at the first visit were reviewed with a full bladder (urine held overnight or for at least three hours), and a further total of $21.5 \%$ were found to have a scanty, mucoid, urethral discharge.

\section{REASONS FOR EXCLUSION FROM}

THE TRIAL

A total of 194 patients had to be excluded from the trial. Of these four vomited doxycycline soon after the single dose of $300 \mathrm{mg}$ had been given; four were subsequently found to have meatal warts; eight reappeared with gonococcal infection after defaulting; 85 did not complete treatment; and the followup period for the remaining 93 was considered to be inadequate-that is, less than two weeks after the completion of treatment.

\section{DEFAULT RATE AND DIFFERENCES}

BETWEEN PATIENTS FOLLOWED UP AND NOT FOLLOWED UP

The differences between those patients who were followed up and those not followed up were very small in respect of past history, symptoms, duration of symptoms, and presence of urethral discharge, which, as pointed out earlier, might affect the outcome of treatment.

The pattern of default rate affected the assessment of patients in group 3 unfavourably. Although patients were asked to return for follow up at one, two, three, five, eight, and 12 weeks many did not observe this routine. As only a week's supply of the drug was dispensed at a time, the irregular attendance meant that 84 out of 258 of those belonging to group 3 had to be excluded. Consequently the numbers in this group who were available for final assessment were lower than in the other groups (Table 1).

\section{Attendance of sexual contacts}

One hundred and fifty-five sexual contacts (mainly wives and girlfriends) of 151 patients attended female clinics at the Liverpool Royal Infirmary. Twenty-eight $(18 \%)$ of these patients compared with $166(27 \%$ of 605$)$ whose sexual contacts were

Table 1 Total number of patients retreated compared with the number followed up and significance of difference between retreatment rates with doxycycline (single dose) and each of the five remaining regimens

\begin{tabular}{|c|c|c|c|c|c|c|c|}
\hline \multirow{3}{*}{$\begin{array}{l}\text { Treatment regimen } \\
\text { and patient group }\end{array}$} & \multirow{3}{*}{$\begin{array}{l}\text { Duration } \\
\text { (days) }\end{array}$} & \multicolumn{3}{|c|}{ No. of patients } & & & \multirow{3}{*}{$\begin{array}{l}\chi^{2} \text { test }^{*}(\text { with } \\
\text { correction) }\end{array}$} \\
\hline & & \multirow[t]{2}{*}{ Followed up } & \multicolumn{2}{|c|}{ Retreated at (weeks) } & \multicolumn{2}{|c|}{ Total retreated } & \\
\hline & & & $3-4$ & $5-12$ & No. & $\%$ & \\
\hline \multicolumn{8}{|l|}{ Group 1} \\
\hline \multicolumn{8}{|l|}{ Group 2} \\
\hline Triple tetracycline & 7 & 120 & 14 & 22 & 36 & 30 & $12 \cdot 98$ \\
\hline Oxytetracycline & 7 & 127 & 10 & 18 & 28 & 22 & 22.6 \\
\hline Doxycycline & 7 & 113 & 16 & 14 & 30 & 26 & $16 \cdot 12$ \\
\hline \multicolumn{8}{|l|}{ Group 3} \\
\hline Triple tetracycline & 21 & 72 & 0 & 11 & 11 & 15 & $25 \cdot 39$ \\
\hline Oxytetracycline & 21 & 85 & 2 & 17 & 19 & 22 & $18 \cdot 57$ \\
\hline Total & - & 562 & 62 & 90 & 152 & 27 & \\
\hline
\end{tabular}

$* \mathbf{P}=<0.001$ 
not known to have attended clinics at Liverpool or elsewhere defaulted. This difference was significant $\left(\varkappa^{2} 4.55 ; \mathrm{P}<0.05\right)$.

\section{Diagnoses of sexual contacts}

When the distribution of diagnoses among sexual contacts was matched with various treatment regimens in the men no significant difference was found. Cervical swabs from 122 female sexual contacts were taken for $C$. trachomatis isolation and $52(42.6 \%)$ gave positive results. The collection of swabs for Chlamydia depended on which day the contact attended, as the facility was not available every day of the week. Yeasts and Trichomonas vaginalis were also found in six and 14 contacts respectively.

\section{RETREATMENT RATES}

Table 1 shows the total number of patients retreated compared with the number followed up in respect of each regimen as well as, individually, the number of those retreated at three to four weeks and at five to 12 weeks. Table 2 shows the corresponding figures after those who admitted to sexual intercourse during the follow-up period have been excluded.

The retreatment rates for group 3, three to four weeks after the start of treatment, were very small (triple tetracycline, nil, and oxytetracycline 2.3$4 \cdot 2 \%$ ) (Tables 1 and 2 ). Doxycycline in a single dose of $300 \mathrm{mg}$ gave very high retreatment rates (over $60 \%$, whether or not those admitted having sexual intercourse are included or excluded). This observation caused considerable concern and the single-dose regimen of doxycycline was immediately abandoned. This rate was significantly higher than that for any of the five remaining regimens whether those who admitted to sexual intercourse are included or excluded $(\mathbf{P}<0.001$ in each case $)$.
As regards the retreatment rates for the other regimens, the difference between the retreatment rates for triple tetracycline (seven-day regimen) and triple tetracycline (21-day regimen) was significant $\left(\%_{1}^{2} 4 \cdot 50: P<0 \cdot 05\right)$. The differences between the remaining retreatment rates were not significant. If all those who admitted sexual intercourse, however, were excluded (Table 2), the retreatment rates for group 3 were low. The rates with triple tetracycline (21-day regimen) were significantly better than with triple tetracycline (seven-day regimen) $\left(\%^{2} 5.004: \mathrm{P}<0.05\right)$ or for doxycycline (sevenday regimen) $\left(\chi_{1}^{2} 6 \cdot 796: p<0 \cdot 01\right)$. Differences between the remaining retreatment rates were not significant. Thus the difference between the retreatment rate with oxytetracycline (seven-day regimen) $(22 \%$ in Table 1 and $16.6 \%$ in Table 2$)$ and that with either oxytetracycline or triple tetracycline (21-day regimen) was not significant. Differences in the retreatment rates at three to four weeks showed similar patterns.

\section{Effect of sexual intercourse on the outcome of treatment}

Of the 562 patients followed up 349 denied having sexual intercourse during the period of surveillance. Of these 44 had resumed sexual activity using a sheath whereas $169(30 \%)$ were having unprotected sexual intercourse, 56 of these (33\% of 169) having done so within three weeks of starting treatment. After those who claimed to be having sexual intercourse using a sheath are excluded, of the 143 patients who were retreated $66(46.2 \%)$ admitted to unprotected sexual intercourse compared with 103 $(27.5 \%$ of 375$)$ who did not require retreatment. This difference was significant $\left(\chi_{1}{ }^{2} 15 \cdot 607 ; \mathrm{P}<0.001\right)$.

Table 3 shows the effect of sexual intercourse on the outcome of treatment with each treatment regimen. In all groups except group 1 more of those

Table 2 Number of patients retreated who denied sexual intercourse during the follow-up period and significance of difference between retreatment rates for doxycycline (single dose) and each of the five remaining regimens

\begin{tabular}{|c|c|c|c|c|c|c|c|}
\hline \multirow{3}{*}{$\begin{array}{l}\text { Treatment regimen } \\
\text { and patient group }\end{array}$} & \multirow{3}{*}{ Duration (days) } & \multicolumn{3}{|c|}{ No. of patierts } & & & \multirow{3}{*}{$\begin{array}{l}\chi^{2} \text { test* (with Yates's } \\
\text { correction) }\end{array}$} \\
\hline & & \multirow[t]{2}{*}{ Followed up } & \multicolumn{2}{|c|}{ Retreated at (weeks) } & \multicolumn{2}{|c|}{ Total retreated } & \\
\hline & & & $3-4$ & $5-12$ & No. & $\%$ & \\
\hline \multicolumn{8}{|l|}{ Group 1} \\
\hline $\begin{array}{l}\text { Doxycycline } \\
\text { Group } 2\end{array}$ & \multicolumn{6}{|c|}{ Group 2} & 一 \\
\hline Triple tetracycline & 7 & 80 & 12 & 6 & 18 & $22 \cdot 5$ & $19 \cdot 68$ \\
\hline Oxytetracycline & 7 & 72 & 7 & 5 & 12 & $16 \cdot 6$ & $25 \cdot 32$ \\
\hline Doxycycline & 7 & 80 & 14 & 6 & 20 & 25 & $17 \cdot 23$ \\
\hline \multicolumn{8}{|l|}{ Group 3} \\
\hline Triple tetracycline & 21 & 42 & 0 & 2 & 2 & $4 \cdot 8$ & $31 \cdot 62$ \\
\hline Oxytetracycline & 21 & 47 & 2 & 3 & 5 & $10 \cdot 6$ & $26 \cdot 50$ \\
\hline Total & & 349 & 51 & 26 & 77 & 22 & \\
\hline
\end{tabular}

${ }^{*} \mathrm{P}=<0.001$ 
Table 3 Effect of unprotected sexual intercourse on the outcome of treatment

\begin{tabular}{|c|c|c|c|c|c|c|c|c|}
\hline \multirow{3}{*}{$\begin{array}{l}\text { Treatment regimen } \\
\text { and patient group }\end{array}$} & \multirow{3}{*}{$\begin{array}{l}\text { Duration } \\
\text { (days) }\end{array}$} & \multirow{3}{*}{$\begin{array}{l}\text { No. of patients } \\
\text { followed up }\end{array}$} & \multicolumn{3}{|c|}{ Not retreated } & \multicolumn{3}{|c|}{ Retreated } \\
\hline & & & \multirow[t]{2}{*}{ Total } & \multicolumn{2}{|c|}{ No sheath used } & \multirow[t]{2}{*}{ Total } & \multicolumn{2}{|c|}{ No sheath used } \\
\hline & & & & No. & $\%$ & & No. & $\%$ \\
\hline \multicolumn{9}{|l|}{ Group 1} \\
\hline Doxycycline & single dose & 38 & 13 & 5 & $38 \cdot 5$ & 25 & 5 & 20 \\
\hline \multicolumn{9}{|l|}{ Group 2} \\
\hline Triple tetracycline & 7 & 116 & 81 & 19 & $23 \cdot 4$ & 35 & 17 & $48 \cdot 6$ \\
\hline Oxytetracycline & 7 & 118 & 91 & 31 & 34 & 27 & 15 & $55 \cdot 5$ \\
\hline Doxycycline & 7 & 102 & 75 & 15 & 20 & 27 & 7 & 26 \\
\hline \multicolumn{9}{|l|}{ Group 3} \\
\hline Triple tetracycline & 21 & 66 & 56 & 16 & $28 \cdot 5$ & 10 & 8 & 80 \\
\hline Oxytetracycline & 21 & 78 & 59 & 17 & 29 & 19 & 14 & 74 \\
\hline Total & & 518 & 375 & 103 & $27 \cdot 5$ & 143 & 66 & $46 \cdot 2$ \\
\hline
\end{tabular}

patients who were retreated had had unprotected sexual intercourse before retreatment than those who did not require retreatment. The differences were significant for oxytetracycline (21-day regimen) $\left(\chi_{1}{ }^{2} 10.281 ; P<0.01\right)$, triple tetracycline (seven-day regimen) $\left(\chi_{1}^{2} 6.076 ; P<0.02\right)$, and triple tetracyline (21-day regimen) $\left(\chi_{1}{ }^{2} 7.602 ; P<0.02\right)$. In group 1 , the number who had had sexual intercourse was very small and many of the retreatments ( 20 out of 28 ) had been given within the first three weeks, by which time only three patients had had sexual intercourse.

Further evidence of the effect of sexual intercourse, as well as the effect of treatment of female sexual contacts on the retreatment rate of men, was obtained from the histories and clinical details (diagnosis and treatment) of the female contacts who attended the clinics at the Liverpool Royal Infirmary. After 32 female contacts of men who defaulted had been excluded, details of 123 women were analysed against each treatment regimen administered to men. Fifty three of the contacts were wives, and most of the remaining were regular girlfriends. As the numbers of men in the various treatment groups whose contacts attended were very small only the total figures for each of the relevant variables are given (Table 4). Eleven female sexual contacts of the men given the single-dose of doxycycline, for whom sexual intercourse had no bearing on the retreatment rate, have been excluded from Table 4 . Of the 48 men who denied having had sexual intercourse during the follow-up period, $18(37 \%)$ were retreated compared with three out of $10(33 \%)$ who admitted to sexual intercourse using a sheath and $30(55 \%)$ of the 54 who had had unprotected intercourse. The differences were not significant, but some patients may have been unreliable witnesses. Comparisons among those who admitted to unprotected sexual intercourse, therefore, might be more valid. Thus, of those who had unprotected sexual intercourse, only six $(25 \%)$ of the 24 whose contacts had received treatment before further sexual intercourse were retreated compared with $24(80 \%)$ of 30 whose contacts were either treated

Table 4 Effect of sexual intercourse on the outcome of treatment in male patients in relation to diagnosis and treatment of sexual contact

\begin{tabular}{|c|c|c|c|c|c|c|c|c|}
\hline \multirow[b]{3}{*}{$\begin{array}{l}\text { Diagnosis of sexual } \\
\text { contact }\end{array}$} & \multicolumn{8}{|c|}{ Details of sexual intercourse in male patients } \\
\hline & \multicolumn{2}{|c|}{ None or using sheath } & \multicolumn{6}{|l|}{ No sheath used } \\
\hline & Total no. & $\begin{array}{l}\text { No. } \\
\text { retreated }\end{array}$ & $\begin{array}{l}\text { No. of men } \\
\text { (contact not } \\
\text { treated or treated } \\
\text { after further } \\
\text { intercourse) }\end{array}$ & $\begin{array}{l}\text { No. } \\
\text { retreated }\end{array}$ & $\begin{array}{l}\text { No. of men } \\
\text { (contact } \\
\text { treated } \\
\text { before } \\
\text { further } \\
\text { intercourse) }\end{array}$ & $\begin{array}{l}\text { No. } \\
\text { retreated }\end{array}$ & Total no. & $\begin{array}{l}\text { No. } \\
\text { retreated }\end{array}$ \\
\hline No STD & 26 & 9 & 17 & 14 & 8 & 2 & 25 & 16 \\
\hline $\begin{array}{l}\text { Chlamydial infection } \\
\text { Chlamydial infection }\end{array}$ & 12 & 2 & 7 & 5 & 8 & 1 & 15 & 6 \\
\hline $\begin{array}{l}\text { and trichomoniasis } \\
\text { Chlamydial infection }\end{array}$ & 4 & 3 & 3 & 3 & 3 & 1 & 6 & 4 \\
\hline and candidosis & 4 & - & 一 & - & 1 & 1 & 1 & 1 \\
\hline Candidosis & 6 & 4 & 3 & 2 & 2 & - & 5 & 2 \\
\hline Trichomoniasis & 4 & 3 & 一 & 一 & - & - & - & - \\
\hline
\end{tabular}


after further sexual intercourse had taken place (15 out of 19) or not treated at all (nine out of 11); the difference was significant $\left(\chi_{1}{ }^{2} 14 \cdot 183 ; P<0.001\right)$. Thus it seems logical to exclude patients who had sexual intercourse during the follow-up period before the effects of other factors on the outcome of treatment are assessed.

\section{EFFECT OF ALCOHOL AND OTHER FACTORS ON THE OUTCOME OF TREATMENT \\ Alcohol}

Three hundred and sixty-five $(64.9 \%)$ out of 562 patients followed up had resumed drinking alcohol during the period of surveillance. Of these, 232 $(63.7 \%$ of 365$)$ had done so within three weeks of starting treatment.

Of the 169 who had had unprotected sexual intercourse, $161(95 \%)$ had also drunk alcohol as opposed to $164(47 \%$ of 349$)$ who had abstained from sexual intercourse. This difference was highly significant $\left(\chi_{1}^{2} 111 \cdot 456 ; \mathrm{p}<0.0001\right)$. Of the 44 who had sexual intercourse using a sheath, only four had abstained from alcohol. Alcohol and intercourse, therefore do seem to go together. The effect of alcohol on the outcome of treatment among those who had had sexual intercourse cannot be assessed, since over $95 \%$ had drunk alcohol. Nevertheless, of the eight who had not drunk alcohol and had unprotected sex, three were retreated; and of the four who claimed to have had intercourse using a sheath one was retreated.

The effect of alcohol on the outcome of treatment may, however, be assessed among the remaining 349 , who, as far as is known, had not had sexual intercourse (Table 5). Thus, of the 272 who were not retreated, $131(48.2 \%)$ had taken alcohol compared with $33(43 \%$ of 77$)$ who were retreated-that is, more of those who were not retreated had consumed alcohol-but the difference was not significant. Whether the patient started to drink within or after three weeks of starting treatment did not seem to make much difference, the retreatment rates being $21 \%$ and $18 \%$ respectively. As regards the individual treatment regimens, no clearcut pattern emerged.

\section{Other factors}

Factors such as age, race, past history of NSU and duration of symptoms did not seem to have any influence on the retreatment rate. There was, however, a greater tendency for retreatment in those patients who had more severe symptoms (dysuria plus urethral discharge) or a frankly purulent urethral discharge. But the differences were not significant.

\section{Discussion}

Doxycycline in a single dose of $\mathbf{3 0 0} \mathrm{mg}$ was followed by the highest retreatment rate. This result was no better than the 'cure' rate of $34 \%$ with a placebo (Fowler, 1970). Masterton and Schofield (1972) claimed to have achieved a 'cure' rate of $93.3 \%$. The reason for this enormous difference in response is not clear. We had to abandon the doxycycline single-dose regimen after only 58 patients had been treated. Many of these patients remained symptomatic or had a symptomatic relapse with evidence of urethritis within one to two weeks after receiving the single dose. We consider this high failure rate a result of suboptimal dose and duration. The retreatment rate with this regimen was not influenced by sexual intercourse. Whether these patients continue to remain infectious remains to be determined. The clinical severity of the relapse in most cases suggested they would be. In the trial of Masterton and Schofield (1972) 'sixteen patients vomited and eight were nauseated out of 156 patients given vibramycin capsules'. Later they say, 'the incidence of side effects is low'. Their figures of side effects certainly cannot be equated with a low

Table 5 Effect of alcohol on the outcome of treatment excluding patients who admitted to sexual intercourse during follow-up period

\begin{tabular}{|c|c|c|c|c|c|c|c|c|}
\hline \multirow{3}{*}{$\begin{array}{l}\text { Treatment regimen and } \\
\text { patient group }\end{array}$} & \multirow{3}{*}{$\begin{array}{l}\text { Duration } \\
\text { (days) }\end{array}$} & \multicolumn{3}{|c|}{ No. of patients not retreated } & \multicolumn{3}{|c|}{ No. of patients retreated } & \multirow{3}{*}{$\begin{array}{l}\text { Total } \\
\text { followed up }\end{array}$} \\
\hline & & \multirow[t]{2}{*}{ Total } & \multicolumn{2}{|c|}{ Consumed alcohol } & \multirow[t]{2}{*}{ Total } & \multicolumn{2}{|c|}{ Consumed alcohol } & \\
\hline & & & No. & $\%$ & & No. & $\%$ & \\
\hline \multicolumn{9}{|l|}{ Group 1} \\
\hline Doxycycline & singie dose & 8 & 3 & 37 & 20 & 4 & 20 & 28 \\
\hline Triple tetracycline & 7 & 62 & 25 & 40 & 18 & 11 & 61 & 80 \\
\hline Oxytetracycline & 7 & 60 & 27 & 45 & 12 & 7 & 58 & 72 \\
\hline Doxycycline & 7 & 60 & 24 & 40 & 20 & 7 & 35 & 80 \\
\hline \multicolumn{9}{|l|}{ Group 3} \\
\hline Triple tetracycline & 21 & 40 & 24 & 60 & 2 & 2 & 100 & 42 \\
\hline Oxytetracycline & 21 & 42 & 28 & 66 & 5 & 2 & 40 & 47 \\
\hline Total & & 272 & 131 & $48 \cdot 2$ & 77 & 33 & 43 & 349 \\
\hline
\end{tabular}


incidence. At least four of our patients vomited before leaving the clinic after taking doxycycline capsules (two having done so after swallowing the capsules with reconstituted milk-a procedure which Masterton and Schofield (1972) found helpful in the control of nausea and vomiting).

Among seven-day regimens oxytetracycline for seven days gave the lowest retreatment rate. Differences in the retreatment rates with the three sevenday regimens in this survey were not, however, significant. Willcox (1972) reported a failure rate of $28.6 \%$ with triple tetracycline, one tablet twice daily for six days, compared with $30 \%$ in this study after seven days' treatment. Doxycycline for seven days gave equally high failure rates. Lassus et al (1971), using doxycycline in a similar dosage but for only five days, obtained a 'cure' rate of over $93 \%$ after a follow up of 14 to 21 days. The corresponding rate after seven days' treatment in our study was $85.9 \%$.

Although oxytetracycline for 21 days gave better results than any of the seven-day regimens, especially after those who had admitted sexual intercourse during surveillance had been excluded, the differences were not significant. Thus an increase in the duration of oxytetracycline treatment to 21 days did not result in any significant advantage over oxytetracycline given for seven days, as noted earlier by Helmy and Fowler (1975). Triple tetracycline for 21 days in this study, however, gave significantly better results than triple tetracycline for seven days whether in respect of all cases followed up or after those who had sexual intercourse during surveillance had been excluded. Triple tetracyline for 21 days also gave significantly better results than doxycycline for seven days after those who had sexual intercourse had been excluded $\left(\chi_{1}{ }^{2} 6 \cdot 796 ; p<0.01\right)$. Our $15 \%$ retreatment rate with triple tetracycline $300 \mathrm{mg}$ twice daily for 21 days was better than the $24 \%$ rate reported by Helmy and Fowler (1975) who used the same dose three times a day for three weeks.

Thus it may be concluded that doxycycline in a single dose has no place in the treatment of NSU. Triple tetracycline for seven days and doxycycline for seven days are also better avoided. There is no difference in efficacy between oxytetracycline for 21 days and triple tetracycline for 21 days, except the cost and the convenience. Triple tetracycline is more expensive but its twice-daily dosage is more convenient. Oxytetracycline for seven days compared favourably with both the 21-day regimens. Perhaps two weeks' treatment might be nearer the optimum duration.

Prolonged courses of tetracyclines have disadvantages. Firstly, they have no application in most parts of the developing countries except in only a few selected cases. Secondly, they have the potential to alter the bowel flora with the emergence of resistant micro-organisms.

Fowler (1970) suggested the recurrences to be relapses rather than reinfections. Handsfield et al (1976), who studied chlamydial infections in men and women, considered the later recurrences to be reinfections and suggested some of the early recurrences could also be attributed to reinfection by an organism with a shorter incubation period. In this study, of the 90 patients retreated after five weeks (almost all of them being recurrences) 64 were associated with sexual intercourse compared with only 11 of the 62 retreated at three to four weeks. This significant association between retreatment and sexual intercourse suggests reinfection. Preliminary observations in relation to chlamydial infections show similar trends (Arya and Mallinson, unpublished report). Whether the sexual intercourse took place with the same or different partner was not recorded in many cases. This whole aspect was studied in greater depth for the 112 men whose sexual contacts were examined and who were themselves followed up for a variable length of time. The retreatment rates in men were significantly lower if the female contact was treated before further sexual intercourse than if sexual intercourse took place before she was treated. Examination and treatment of sexual contacts are, therefore, as logical in this condition as in any other sexually transmitted disease.

Few people, if any, believe today that alcohol causes urethritis. Despite lack of supportive evidence it remains standard teaching that alcohol may delay the resolution of an established case (Harkness, 1950) or cause a relapse (Catterall, 1974). Less than $2 \%$ of alcohol is excreted in the urine (Kalant, 1973). Although a known gastric irritant, its effects on urethral mucosa is unknown. In this study alcohol did not seem to have an important bearing on the outcome of treatment. This finding, however, was biased by the fact that every patient was advised to abstain from alcohol for at least three weeks. Although this advice was ignored by many, it might have resulted in much smaller quantities than usual being consumed. This study does nevertheless indicate the need to investigate this factor more thoroughly. Alcohol may certainly promote sexual activity by lowering inhibitions. Supportive evidence for this was found in that $95 \%$ of those who had unprotected sexual intercourse during the follow-up period in this study had also drunk alcohol. This biological interaction of ethanol and man at behavioural level is universally accepted as a reason for advising patients to abstain from alcohol in the management of NSU. 
None of the treatment regimens showed any significant trends in relation to the other factors observed in this study, namely, the duration of symptoms, the severity of symptoms and signs, and the past history of NSU. Similar observations had earlier been made by Evans (1977). Thus, on the evidence available the optimum duration of treatment for an individual patient could not be predicted. A much larger study, however, might provide a more conclusive answer.

We would like to express our thanks to the medical and nursing staff at the Seamen's Dispensary and to the medicosocial and clerical staff both at the Seamen's Dispensary and the Liverpool Royal Infirmary for their invaluable help. We would also like to thank our colleague Dr Elizabeth Rees for allowing us access to her case sheets, and $\mathrm{Mr}$ M. C. K. Tweedie and Mr C. West for advice on some of the statistical aspects.

\section{References}

Alergant, C. D. (1964). Single-dose treatment of non-specific urethritis. British Journal of Venereal Diseases, 40, 266-267.

Arya, O.P. (1972). Some highlights on the aetiology of non-gonococcal urethral discharge in males in Kampala, Uganda. East African Medical Journal, 49, 817-824.

British Medical Journal (1971). Editorial: Management of nonspecific urethritis, British Medical Journal, 3, 62.

Catterall, R. D. (1974). A Short Textbook of Venereology, second edition, p. 53, English Universities Press: London.

Department of Health and Social Security (1976). Sexually transmitted diseases. British Journal of Venereal Diseases, 52, 351-354.

Evans, B. A. (1977). The role of tetracyclines in the treatment of non-specific urethritis. British Journal of Venereal Diseases, 53, 40-43.
Fowler, W. (1970). Studies in nongonococcal urethritis therapy. The long term value of tetracycline. British Journal of Venereal Diseases, 46, 464-468.

Handsfield, H. H., Alexander, E. R., Wang, P. S., Pedersen, A. H. B., and Holmes, K. K. (1976). Differences in the therapeutic response to Chlamydia-positive and Chlamydia-negative forms of nongonococcal urethritis. Journal of the American Venereal Disease Association, 2, 5-9.

Harkness, A. H. (1950). Non-gonococcal Urethritis. pp. 298 and 374, Livingstone: Edinburgh.

Helmy, N., and Fowler, W. (1975). Intensive and prolonged tetracycline therapy in non-specific urethritis. British Journal of Venereal Diseases, 51, 336-339.

Holmes, K. K., Handsfield, H. H., Wang, S. P., Wentworth, B. B., Turck, M. Anderson, J. B., and Alexander, E. R. (1975). Aetiology of non-gonococcal urethritis. New England Journal of Medicine, 292, 1199-2005.

John, J. (1971). Efficacy of prolonged regimes of oxytetracycline in the treatment of non-gonococcal urethritis. British Journal of Venereal Diseases, 47, 266-268.

Kalant, H. (1973). Absorption, diffusion, distribution, and elimination of alcohol. In The Biology of Alcoholism, volume 1, pp. 1-46. Edited by Benjamin Kissin and Henri Begleiter. Plenum Press: New York.

King, A. (1964). Recent Advances in Venereology. p. 378, Churchill: London.

Lassus, A., Perko, R. L., Stubb, S., Mattila, R., and Jansson, E. (1971). Doxycycline treatment of nongonococcal urethritis with special reference to T-strain mycoplasmas. British Journal of Venereal Diseases, 47, 126-130.

Mahony, J. D. H., Harris, J. R. W., and Dougan, H. J. (1972). Preliminary study of combined sulfametopyrazine and streptomycin single-dose therapy in nongonococcal urethritis. British Journal of Clinical Practice, 26, 173-174.

Masterton, G., and Schofield, C. B. S. (1972). Doxycycline $\mathrm{HCl}$ (Vibramycin) as a single dose oral treatment of gonococcal and nonspecific urethritis in men. British Journal of Venereal Diseases, 48, $121-125$.

Oriel, J. D., Reeve, P., Wright, J. T., and Owen, J. (1976). Chlamydial infection of the male urethra. British Journal of Venereal Diseases, $52,46-51$.

Osoba, A. O. (1972). Epidemiology of urethritis in Ibadan. British Journal of Venereal Diseases, 48, 116-120.

Wiesner, P. J. (1977). Selected aspects of the epidemiology of nongonococcal urethritis. In Nongonococcal Urethritis and Related Infections, pp. 9-14. Edited by D. Hobson and K. K. Holmes. American Society for Microbiology: Washington, D.C.

Willcox, R. R. (1972). 'Triple tetracycline' in the treatment of nongonococcal urethritis in males. British Journal of Venereal Diseases, 48, 137-140. 